\title{
Analysis on Curriculum Reform of Physical Education Major in Universities
}

\author{
Xiaohui Sun ${ }^{1, a}$ \\ ${ }^{1}$ Qingdao Huanghai University, Qingdao, 266427 \\ a email
}

\section{Keywords: Physical Education, Curriculum Reform, Student Development}

\begin{abstract}
Since the founding of Chinese sports (Education) Professional respectively in 1955, 1963, 1980, 1986, 1991, 1997, several adjustments lesson plans, curriculum reform. Despite some achievements, but overall analysis, there are still some problems, such as professional too strong, lack of normal, academic deficiencies, lack of flexibility, adaptability is not strong and other issues. The reason is mainly influenced by the traditional curriculum ideas too, especially in the former Soviet Union and curriculum planning mode concept Special Education Curriculum economic system is still dominated by this concept curriculum and market economy is now out of tune of. Thus, to change the traditional concepts of education, establish advanced and modern philosophy courses with the times is the key to professional sports curricular reform.
\end{abstract}

\section{Introduction}

The 21st century is knowledge economy as the main economy in order to create the soul of all walks of life to the information age into the social characteristics of the 21st century, social quality of talent put forward new and higher requirements. With education "toward modernization, the world and the future," the guiding ideology of the progressive implementation of PE in China and the deepening of the reform process, thick foundation, wide caliber, high-quality, strong ability to adapt to a wide and heavy physical education innovation talent is becoming urgent needs of social development. Therefore, the undergraduate College Physical Education should be adapted to the new requirements of social development for sports personnel training; adapt education reform, especially the "Basic Education Curriculum Reform" and "Health first" new school education requirements for Physical Education Reform ; adapt sports reform, in particular the implementation of the National health plan under the new situation, to achieve a general increase in the new national quality requirements. Under this background, the College Physical Education Instructional Content and Course System of deepening reform of education are both an opportunity and a challenge. For a long time, Chinese higher education reforms have been guided by a "reform is the key to teaching reform is the core, the purpose is to improve the quality and changing concepts is a prerequisite for reform ideas. Courses are both important way to achieve training objectives, teaching is a breakthrough in the reform, so reform of higher education around the world first of all start from the curriculum reform. College Curriculum Reform is a complex systematic project, subject to many factors. Xu Jian collar is that the reform of university curriculum to modern ideas, concepts, values, unifying curriculum development to better resolve the relationship between social needs, discipline development (knowledge) and among individuals, so that the various elements in the system of Higher Education Course structural link in the show overall effect Chuan. From the perspective of cultural studies, the university curriculum system includes a portion of the material level, the institutional level, the main level and value level four interrelated. In these four levels, the substance is the base level, the system level provides the management and support, the main level is a necessary condition indispensable, while the value of level is the heart and soul. Key Curriculum reform is whether deep into the value level, it relates to the value of traditional influence, related to the course subject of different values, modern curriculum value level is the recognition of curriculum value of the current of the main body, the traditional curriculum Value contradictory movement of the times and social development between. Any reform idea is a pilot. Course 
curriculum reform body needs to get rid of the traditional concept of course, the concept of setting up the course of modernization. Establish the concept in line with modern requirements of the course is to deepen the reform of Physical Education Curriculum important prerequisite.

\section{Development of Higher Education and Its Influence on Curriculum Reform of Physical Education Major}

Curriculum reform is important and difficult reform of education, philosophy of education is a broader concept curriculum concept of development is bound to change in educational philosophy reflected among curriculum reform to become a factor in the concept of curriculum reform. Physical Education is an integral part of higher education, therefore, seize the reform of higher education general guiding principle, will grasp the concept of macro Higher Physical Education Curriculum Reform. The world over, such as the reform of higher education fiery tea, many educational philosophy have emerged, the main concept of lifelong education, philosophy of education for sustainable development, education philosophy of personalized, innovative educational concept, the main concept of education, quality education, Education International The concept and the like. From the content of these ideas covered view, which itself is interrelated and mutually inclusive, some even in essence is the same, therefore, the present study only in respect of a few typical representative of the philosophy of education were discussed.

The concept of quality education and curriculum reform of physical education. In sports education, sports education from different scholars were education, psychology, sociology and human studies on physical education in quality education were discussed. For example, some believe, from the sport "examination-oriented education" to sport "quality education", it is from the "present" to "the people" shift the center of gravity is the transfer of physical education. From a psychological point of view, it was considered the transfer of knowledge to the physical education heavier and heavier weight capacity and then the quality of the center of gravity, so that physical education closer to the essence of the concept of change. At the same time, from the perspective of sociology and human studies, scholars have proposed "Social development of sports talents in the new century, higher quality requirements, consider learning to do and learning to be, sports science education and human qualities and harmonious development, and should be in practice combination.

Quality education is reflected in the curriculum, the school is the first place to provide a comprehensive development needs as many courses for students. This course is not only professional education courses, but also the general education and humanities education courses have contained personality development. The arrangement and selection of course content, considering not only theoretical, systematic training and knowledge of issues such as logical thinking, but also concerned about the coordinated development of capacity-building and other non-intellectual factors; curriculum, course structure, curriculum must first consider the goal is to develop the overall quality of talent, rather than a certain threshold of expertise to master. Quality education is a new educational philosophy, understanding and implementation of quality education, to reform the existing higher physical education courses, training sports talents in the 21st century is very necessary. Guiding Ideology Higher Physical Education Curriculum System of education should be the organic integration of general education and professional education, science education and humanities education, to avoid too much emphasis on professional education neglect of basic education, sport science education and humanities education in isolation from sidedness. We must overcome our Curriculum System of Higher Physical presence "heavy paper light weapons," learn to eat around the world of technical shortcomings, nor for the development of the human personality and contempt natural sciences. In the current system of higher physical education curriculum, the humanities education courses, social science courses and science courses should be given equal importance to achieve the perfect combination of general education and sports Physical Education, Physical Education and Sports Science Humanities education, so Higher Physical Education Curriculum structure tends to be more reasonable. 


\section{Construction of College Physical Education Undergraduate Curriculum Scheme}

Updating educational ideas and concepts of science to determine the physical education is professional training objective of the pilot. Updating educational ideas and concepts of the past is to abandon teaching ideas and concepts, through summary and reflection, to carry forward the past useful side, which eliminated outdated educational ideas and concepts. Educational reform ideas and concepts are actually educational phenomenon, and then re-deepening understanding of the nature and law or under the new situation. Reform of educational ideology, to re-examine the talent training plan has laid a good foundation, such as, "quality education" concept requires that the education goals of comprehensive, integrated model of culture, the culture coordination process, "lifelong learning" concept establish requirements for the training process of the stage, the basic continuity and teaching contents, validity, the concept "emphasis on personal development" requires that the education and training of diverse models of relaxed environment.

Faced with the progress of the development of the new century, social education, face a new round of basic education curriculum reform, social development must be based on different levels, different specifications, different types of high-level expertise of the objective requirements of the physical education major talent Training objectives for accurate positioning. As can be seen from the College Physical Education professionals in training mode Historical Changes, Physical Education Major's position is: First, physical education undergraduate higher education system belongs, in terms of its properties, which should reach the professional undergraduate education the general level and requirements that you must have the professional education of the general characteristics; second, professional and physical education teachers belong to the education system, which requires from the particularity of teacher education system up awareness of Physical Education Major. Based on the above research and understanding of the physical education professionals of culture in the new century put forward new requirements, training objectives expressed in the new physical education specialty new course program as: "Physical Education Major train qualified school physical education, teaching, training and competition work, and to engage in complex Physical Education personnel school sports science, sports management and school social sports guidance work. "

Construction in College Physical Education Curriculum program of the new century, the new structure of the curriculum system, though still in accordance with the required courses and electives to divide, but it reflects the "update concepts of education, strengthen the overall foundation and broaden the professional caliber, cultivate awareness of innovation, enhance the ability to adapt, improve the overall quality, focus on individualized, prominent personality development "characteristics. In the type of course, the focus on coordinating the relationship between required courses and elective form a resilient and diverse curriculum model. Main Course Compulsory Course in Physical Education grant students the most basic core knowledge and skills required courses is generally granted to students engaged in basic knowledge and skills in physical education, and points the direction of elective courses, elective courses by the students according to their own arbitrary strengths, interests, hobbies and social needs to choose. Hours of 6.77:1.95:1.28 proportion of the three required courses compared to 1997 "course program" ratio [2] of the 7:2:1 be adjusted. This change, on the one hand and actively adapt to the reform and development of international higher education and the rapid development of today's knowledge economy needs social, culture "thick foundation, wide caliber, high-quality, wide adaptation, ability, re-innovation" Physical Education Complex talent; on the other hand, take the initiative to adapt to the pace of the new era of reform and development of basic education, reflecting the common characteristics and features of the times China Instructional content and course system of Physical Education Deepening reform. In the main required course, compulsory course and elective course system combining both emphasize the common, without neglecting the personality, so that our College Physical Education Curriculum System structure is more reasonable and scientific.

In undergraduate education teaching contents and curriculum system of college sports reform in our country, a required course for students is to ensure the basic theory, knowledge and skills to master, to ensure that students have a basic knowledge of generous, to further broaden the 
professional caliber. In strengthening basic education, while students focus on practical ability, in view of this, the reform of the existing educational curriculum, educational programs should be expanded categories, increase the amount of hours of education courses, extended practice time education, enable students to form scientific philosophy of education, a solid grasp of educational skills, skills. Increase opportunities for students to participate in social practice, in order to grasp the social development of Physical Education Personnel requirements opportunity to strengthen their knowledge, ability, quality structure development, promote the process of quality education and lifelong learning, so that students get the quality and coordinated development, Construction can adapt to changes in the development of basic education and social needs of the overall quality of construction. Focus on the role of hidden curriculum, guide students to put into practice all kinds of socially oriented basic education in order to enable academic lecture series, standardization, regular, full universities have rich intellectual background and rich cultural heritage, the formation of diligent study, the atmosphere is thinking, exploration and research.

\section{Conclusion}

Concept of higher education in the New Curriculum has big impact on Physical Education Curriculum mainly quality education, the concept of lifelong education, educational concept of personalization and internationalization of education philosophy. The basic idea is now time physical education curriculum are: physical education and health education integration; general education combined with professional education; science education and humanistic education integration; academic and teacher of unity; commonness and personality development.

\section{References}

[1] Li Zhuangzhi, Li Li. Under the new situation and other sports education professional education real learning mode study [J]. Zhejiang sports science, 2008,30 (5): 32-34.

[2] Gu Mingyuan. Education dictionary [M]. Shanghai: Shanghai Education Publishing House, 1998: 14.

[3] Liu Pingqing, Yuan Zuosheng. New "course program [J]. Some College Physical Education Major of Beijing Sport University, 2000, 31 (4): 38-40.

[4] Zhao Jiyang, Zou Xiaoer, Li Jianhua. from the present program of Physical Education Curriculum Survey [J]. Jishou University (Bai Ran SCIENCE), 2008, 29 (l): 12-14.

[5] Wang Yuanbang. PE Undergraduate Capability Analysis and Research of Education Countermeasure [J]. Beijing Sport University, 2006, 29 (6): 18-22.

[6] Xiaowei, Jiang Ling. College Sports Talents Training and demand relationship of Basic Education [J]. Beijing Sport University, 2006, 29 (12): 81-82. 